\title{
Author Correction: NICE's rejection of pembrolizumab for platinum-refractory urothelial carcinoma: is there a greater good?
}

\section{Shilpa Gupta and Ashish M. Kamat}

Nature Reviews Urology (2020) https://doi.org/10.1038/s41585-020-0357-1 Published online 6 July 2020

The originally published article incorrectly stated that the authors declared no competing interests. The competing interests statement has been corrected in the HTML and PDF versions of the manuscript to include A.M.K.'s competing interests, and has been included in this correction.

A.M.K. is a consultant or advisory board member for Abbott Molecular, Arquer Diagnostics, ArTara Therapeutics, Asieris Pharmaceuticals, AstraZeneca, BioClin Therapeutics, Bristol-Myers Squibb, Cepheid, Cold Genesys, Eisai, Engene, Ferring Pharmaceuticals, FerGene, Imagine Pharma, Janssen, MDxHealth, Medac, Merck, Pfizer, Photocure, ProTara Therapeutics, Roviant Sciences, Seattle Genetics, Sessen Bio, Theralase Technologies, TMC Innovation and US Biotest. A.M.K. has received grants and/or research support from Adolor Corporation, Bristol-Myers Squibb, FKD Industries, Heat Biologics, Merck, Photocure, SWOG/NIH, Specialized Programs of Research Excellence (SPORE) and AIBCCR. A.M.K. also holds the patent for Cytokine Predictors of Response to Intravesical Therapy (CyPRIT) joint with UT MD Anderson Cancer Center. S.G. is an advisory board member for Merck.

https://doi.org/10.1038/s41585-020-0361-5 I Published online 27 July 2020

๑) Springer Nature Limited 2020 